\title{
Esteban Mira Caballos, Francisco Pizarro: una nueva visión de la conquista del Perú. Planeta, Barcelona, 2018, p. 412.
}

El autor es especialista en historia de América. No es la primera obra que publica sobre estos temas. Recientemente ha publicado libros sobre personajes de la conquista, como Hernando de Soto, Nicolás de Ovando y Hernán Cortés. Con ese bagaje, Pizarro no sería la excepción.

El libro que reseñamos tiene dos partes muy diferenciadas. La primera es la biografía en sí y la segunda es la parte de fuentes. Primeramente hacemos un breve comentario sobre las fuentes. Es sorprendente cómo el autor presenta un status quaestionis completo sobre el tema a tratar, pues distingue las fuentes antiguas (propias de la época virreinal, como los cronistas y archivos) y las contemporáneas (desde el siglo XVIII a la actualidad). En la biografía contemporánea, recorre autores tanto de lengua hispana como italiana, inglesa y francesa. En el caso de los autores peruanos, destacan José Antonio del Busto, Gustavo Gutiérrez, Guillermo Lohmann, Raúl Porras Barrenechea, José de la Puente Brunke, María Rostworowsky, Rubén Vargas Ugarte, entre otros. Además se debe rescatar el buen trabajo de los apéndices, donde se detallan cifras y datos. Finalmente tiene un pequeño glosario de términos quechuas (topónimos o quechuismos aceptados en castellano de uso en América), que facilita la lectura a aquellas personas que no las conocen, pero que se emplean a lo largo del libro porque son esenciales en el contexto del biografiado.

Respecto del desarrollo de la biografía, el autor retrata - a decir de Ortega y Gasset- el ser y las circunstancias del biografiado. Las circunstancias se notan especialmente en el primer capítulo y en el epílogo. Ahí se narran tanto la situación de la caída y decadencia del Imperio incaico como lo que pasó con la descendencia del conquistador. Los datos de Francisca Pizarro y su posterior matrimonio con Hernando (hermano del conquistador y tío de Francisca) bastan para saber sobre lo que pasó con el linaje del biografiado.

Es especialmente revelador el capítulo 2, denominado "El personaje". En esas líneas, el autor destaca los rasgos de la personalidad del biografiado en varios aspectos de su vida: su formación, su religiosidad, su condición militar y como gobernante. Además realiza un estudio sobre la buena fama del conquistador, desde la época de la Conquista hasta la actualidad, haciendo especial hincapié

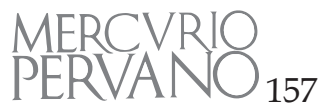


en la propaganda frente a Hernán Cortés. En el resto de capítulos, entre el 2 y el 7 , se narra la vida del conquistador.

Llama la atención la parte final de la biografía, denominada "Conclusiones". En esta parte, el autor hace una especie de 'juicio final' sobre el biografiado y una proyección de la conquista en la actualidad. Aquí, me parece, que el autor cae en metacronismo, es decir, aplica un juicio de hechos y comportamientos pasados con valores contemporáneos. Respecto del biografiado, el mismo autor reconoce varias veces (por ejemplo, en las pp. 40 y 202) que el conquistador actuó como alguien de su tiempo.

Por otro lado, refiere a un supuesto problema de aceptación de la conquista en el imaginario peruano. Incluso señala que es un tema de justicia por unos derechos negados a los indígenas. Sobre esto es importante resaltar dos ideas importantes. La primera: hay en el libro una generalización del comportamiento de los españoles en América, como si la conquista hubiera sido algo malo e injusto. Además de continuar con la leyenda negra, el autor omite señalar algo evidente: el carácter tuitivo del derecho indiano que se perdió con la independencia del Perú. Es innegable que hubo españoles que hicieron caso omiso a estas reglas, pero hubo otros que defendieron a los indígenas. Normalmente fray Bartolomé de las Casas es un ejemplo de esta defensa, pero prefiero poner un ejemplo más cercano y menos teórico: el presbítero bachiller Juan de Mori Alvarado. De él hay un monumento con una placa en la plaza principal de Catacaos, a unos kilómetros de la ciudad de Piura, donde consta que "compró el 20 de julio de 1645 a la Corona de España, gran extensión de terrenos en Catacaos y se los obsequió a los indígenas de este pueblo". Incluso, parte de estas tierras conforman hoy el distrito de Cura Mori, en honor a este sacerdote.

La segunda idea es el mestizaje. Es innegable que gran parte del país es mestizo y que aún quedan poquísimas zonas indígenas, especialmente en la selva. Como prueba de ello, Serge Gruzinski, en su libro El pensamiento mestizo (2000), señala que ya el mestizaje se notaba desde el inicio de la conquista. Además hay que señalar, como mencionaba Víctor Andrés Belaunde, que el mestizaje no es algo estático, sino que es una sintesis viviente. En pleno siglo XXI, se ha agregado el elemento oriental a la síntesis hispánico-indígena en el Perú. Valga como ejemplo la comida tipo chifa o nikkei fusión. Otro ejemplo puede ser el que suscribe la presente biografía: apellido paterno oriental (de Cantón, China), apellido materno autóctono (tallán, del bajo Piura) y nombres en castellano (aunque uno es de origen alemán y el otro, hebreo).

Puede parecer que, tras los comentarios, la conclusión debe ser una crítica al libro. Más bien es todo lo contrario. Con las salvedades antes señaladas, recomiendo su lectura con entusiasmo. 